\title{
Majority Member's Recognition and Protest Against Discrimination of Immigrants: The Role of Power Threat, Deprovincialization and Common National Identity
}

\author{
Maykel Verkuyten ${ }^{1} \cdot$ Borja Martinovic $^{1}$
}

Published online: 20 August 2015

(C) The Author(s) 2015. This article is published with open access at Springerlink.com

\begin{abstract}
Following the social identity perspective and using data from two national surveys, the present research examines among the native Dutch their recognition of discrimination against immigrants (Study 1) and their intention to protest against this (Study 2). It was found that stronger endorsement of a common national identity was associated with higher recognition and stronger protest intention. However, higher perceived power threat was associated with lower common identity endorsement and thereby to lower recognition of discrimination and reduced willingness to protest. At the same time, a less in-group centric perspective (deprovincialization) was associated with higher recognition of discrimination and willingness to protest because of a stronger endorsement of common identity. The similar results in the two studies support the generality of the proposed processes and add to the limited research on when and why majority members recognize and act against group-based injustices.
\end{abstract}

Keywords Discrimination · Protest - Dual identity · Power threat · Deprovincialization

\section{Introduction}

Discrimination implies unequal treatment and is an important mechanism for establishing and maintaining group-based social hierarchies (Sidanius \& Pratto, 1999). Discrimination of immigrants and ethnic minorities creates structural barriers to, for example, education, employment, income, housing and medical care. There is a large literature on the negative psychological consequences of being a target of

Maykel Verkuyten

m.verkuyten@uu.nl

1 Department of Interdisciplinary Social Science, Faculty of Social and Behavioural Sciences, Ercomer, Utrecht University, Padualaan 14, Room B2.11, 3584 CH Utrecht, The Netherlands 
discrimination (see Major, Quinton, \& McCoy, 2002; Schmitt \& Branscombe, 2002) and an even larger literature on the causes and correlates of prejudicial attitudes and discriminatory behavior (see Dovidio, Hewstone, Glick, \& Esses, 2010). There also is research on how minority members cope with the discrimination they face, including collective action and protest (e.g., Fleischmann, Phalet, \& Klein, 2011; Van Zomeren, Postmes, \& Spears, 2008). The endorsement of and participation in actions that aim to improve the rights, power and influence of one's disadvantaged minority group can play an important role in challenging and changing discriminatory practices (Tajfel \& Turner, 1979).

Successful social change also requires that the advantaged group recognize discrimination and the resulting unfairness of the hierarchical situation. Arguably, this recognition and the willingness of majority members to join in collective action against discrimination is just as important for changing intergroup relations (Subašić, Reynolds, \& Turner, 2008). However, more work is needed on majority group members' willingness to become actively involved in fighting discrimination (Banfield \& Dovidio, 2013; Saguy, Dovidio, \& Pratto, 2008). According to the social identity perspective (Turner \& Reynolds, 2001), psychological change in people's understanding of themselves and others is at the core of social change. It is when majority members redefine the minority as an in-group that political solidarity with the minority is likely (Subašić et al., 2008). The redefinition of a higher-level common identity depends on people's understanding of their in-group and the outgroup, and the related intergroup boundaries.

The present research examines the role of common national identity for majority members' recognition of discrimination against immigrants and their willingness to protest against it. The key proposition tested is that the endorsement of a shared national identity is associated with higher recognition of discrimination (Study 1) and a stronger intention to protest (Study 2). Furthermore, we consider perceived power threat and the normative meaning of the majority identity as influencing the perception of categorical group boundaries and thereby making the endorsement of a common national identity less or more likely. Higher perceived power threat was expected to be associated with a weaker endorsement of a common national identity, and via common identity to lower discrimination recognition and intention to protest. Additionally, a more deprovincialized (less in-group centric) identity was expected to be related to higher discrimination recognition and intention to protest because of a stronger endorsement of a common identity. Thus, common national identity was examined as a mediator in the relation between perceived power threat and the normative meaning of the in-group identity, on the one hand, and discrimination recognition and protest, on the other hand. The expected associations were examined in the context of the Netherlands and by using data from two national surveys among native Dutch.

\section{Common Identity}

According to the social identity perspective (social identity theory and selfcategorization theory; Tajfel \& Turner, 1979, and Turner, Hogg, Oakes, Reicher, \& Wetherell, 1987), political solidarity becomes possible when the majority shares an 
identity with the minority (Subašić et al., 2008). Solidarity implies higher-level unity whereby the minority is recategorized as in-group. Self-categorization theory (Turner et al., 1987) further argues that the common, superordinate identity provides the comparative context in which subgroup identities are understood. This means that the shared identity does not imply the loss or submergence of subgroup identities within the common in-group but rather captures a sense of unity in diversity: 'solidarity denotes higher-level unity rather than lower level uniformity' (Subašić et al., 2008, p. 337). The emphasis is on the superordinate identity ('unity'), a sense of common belonging, rather than on subgroup differences ('diversity').

This emphasis is similar to the Common Ingroup Identity Model of recategorization (Dovidio, Gaertner, \& Saguy, 2009) that builds on the social identity perspective. This model stresses the importance of a shared identity representation for lower intergroup bias, the recognition of group-based inequality, facilitating justice concerns among majority members, and providing a context for moral inclusion of minorities (Gaertner \& Dovidio, 2000; Tyler \& Blader, 2003). This is especially important for majority members who are more likely to recognize and act against discrimination of minority group members included in a shared national category. ${ }^{1}$ In an experimental context, common identity salience was found to promote willingness to protest on behalf of an ethnic minority member (Banfield \& Dovidio, 2013). Further, survey research among majority members in the USA demonstrated that stronger national identification predicts stronger support for policies to reduce inequities between ethnic minority and majority groups (Smith \& Tyler, 1996), and greater sensitivity to just treatment (Huo, 2003). Yet, these studies did not investigate the endorsement of common identity and did not consider factors that can weaken or strengthen this endorsement. We examined whether a stronger endorsement of a common national identity that acknowledges cultural diversity (unity in diversity) is associated with higher recognition of discrimination of immigrants and stronger willingness to protest against this discrimination. In addition we investigated whether perceived power threat and deprovincialized beliefs are related to common identity endorsement, and thereby to recognition of discrimination and protest intention.

\section{Power Threat}

The concept of threat is central in social psychological theorizing and research on intergroup relations. Social identity threat can take different forms, such as the belief that in-group distinctiveness is undermined, in-group value is questioned, or in-group dominance and power is challenged (Branscombe, Ellemers, Spears, \& Doosje, 1999; Ellemers, Spears, \& Doosje, 2002; Knowles, Lowery, Chow, \& Unzueta, 2014). Individuals employ a range of social identity management

\footnotetext{
1 The survey assessed various other constructs and parts of these data have been analyzed in other papers (e.g., Hindriks, Verkuyten, \& Coenders, 2014; Martinovic \& Verkuyten, 2013; Verkuyten, Martinovic, \& Smeekes, 2014). However, the current theoretical focus and analysis is novel and the findings have not been published previously.
} 
strategies when confronted with these kinds of threat, such as sharpening of group boundaries in trying to clearly differentiate the in-group from other groups.

Acknowledging and challenging discrimination of disadvantaged minority members undermines the maintenance of group-based social hierarchies that favors the advantaged (Sidanius \& Pratto, 1999). Members of advantaged groups tend to desire a stable social system that benefits them (Sidanius \& Pratto, 1999; Tajfel \& Turner, 1979). They are motivated to protect their power position and favor ideologies such as assimilation and color-blindness that serve to justify the status quo (Rattan \& Ambady, 2013; Verkuyten, 2006). They tend to focus on ideologies and identity representations that justify and mask group-based privileges and disparities, and are reluctant to address power differences in interactions with minority members (Saguy et al., 2008). According to the group position model (Blumer, 1958; Bobo, 1999), dominant group members become motivated to defend their advantaged position when they feel a threat to their in-group's status and power. One important response to this threat is the strengthening of subgroup boundaries, which contributes to perceived in-group homogeneity and cohesiveness, and undermines feelings of commonality with out-groups (Ellemers et al., 2002; Wright \& Baray, 2012). Strong subgroup boundaries make intergroup competition more likely than intergroup solidarity, which depends on a shared identity (Subašić et al., 2008; Tajfel \& Turner, 1979). This leads to the expectation that majority members who more strongly perceive that immigrants threaten their group's power will less strongly endorse a common national identity representation that acknowledges cultural diversity and will therefore be less inclined to recognize discrimination of immigrants and protest against it.

\section{Deprovincialization}

The social identity perspective emphasizes that intergroup perceptions and behavior should be understood in relation to the meaning of one's social identity (Turner, 1999; Turner \& Reynolds, 2001). Research has shown, for example, that the way in which people understand their in-group affects out-group tolerance, perceptions of intergroup inequality and its perceived legitimacy, and the intention to become politically active in support of ethnic minority groups (e.g., Reicher, Cassidy, Wolpert, Hopkins, \& Levine, 2006; Smeekes, Verkuyten, \& Poppe, 2012; Subašiç \& Reynolds, 2009).

The meaning of one's social identity can be understood in various ways, such as in terms of historical narratives, self-attributed characteristics, self-defining norms and values, and ideological beliefs (Ashmore, Deaux, \& McLaughlin-Volpe, 2004). For example, majority members tend to be aware of their privileged identity status (Knowles et al., 2014), attribute more positive self-defining characteristics to their in-group, and can consider their in-group culture as providing the self-evident and invariant standard for judgment. In contrast to the latter ethnocentric view with its sharp group boundaries, it is also possible to consider one's in-group culture as only one of the many different and valid ways of perceiving and dealing with the social world. This ideological belief has been described as deprovincialization in social psychology (Pettigrew, 1997; also see Brewer, 2008). It implies a less in-group 
centric understanding, whereby in-group norms and values do not function as the self-evident standards for perceiving and evaluating the world. Having a deprovincial view limits the normative importance of the in-group as the standard for judgment in intergroup comparisons. In the current study we examine the expectation that majority members' with a more deprovincialized view on their in-group culture will more strongly endorse a common national identity that acknowledges cultural diversity and therefore be more inclined to recognize discrimination of immigrants and protest against it.

\section{Study 1}

\section{Method}

\section{Data and Participants ${ }^{2}$}

Participants for Study $1(N=928)$ were from a national sample of the native Dutch population maintained by a Dutch bureau specialized in collecting representative population data. The sample reflected the population in terms of age, gender, education, household size and the region of residence. The participants completed the questionnaire online. The age of the participants ranged from 18 to 88 years $(M=49.84, \mathrm{SD}=17.15)$, and $48 \%$ was female. On a 7 -point scale that corresponds to the Dutch educational system, $3.7 \%$ of the participants indicated that primary education was their highest obtained level of education. $16.2 \%$ completed lower secondary and $4.5 \%$ middle secondary education, $34.8 \%$ had a vocational diploma, $4.9 \%$ completed higher secondary education (preparing students for a university), $23.3 \%$ obtained a Bachelor's degree, and $12.5 \%$ obtained a Master's degree or higher. Based on the political self-placement (Jost, 2006), $28 \%$ of the participants placed themselves at the political left, $44.1 \%$ in the middle, and $27.9 \%$ at the right.

\section{Measures}

The items used for constructing the variables were all measured on a scale ranging from 1 (completely disagree) to 7 (completely agree).

The first independent variable perceived power threat was assessed with three items that emphasize the difference between natives and immigrants: 'Because many immigrants live here, native Dutch people have less and less influence', 'The native Dutch are slowly losing the Netherlands to newcomers', and 'Sometimes it

\footnotetext{
${ }^{2}$ For minority group members a dual identity model that simultaneously emphasizes superordinate and subgroup identities is typically more appropriate and more strongly endorsed (Dovidio et al., 2007; Hornsey \& Hogg, 2000). This is not the case for natives in non-settler countries such as the Netherlands and Germany. One important reason is that the linguistic representations of nationhood and of the native population correspond: Dutch typically means ethnic Dutch (and Germans typically means ethnic Germans). So a dual identity representation is problematic for the native Dutch because they do not consider themselves to have a dual identity (Verkuyten, 2014).
} 
seems like natives have to adjust to newcomers, instead of the other way around' (see Hindriks, Verkuyten, \& Coenders, 2015). The three items were averaged $(\alpha=.90)$ and a higher score indicated more perceived power threat $(M=4.55$, $\mathrm{SD}=1.46)$.

The second independent variable deprovincialization was captured by four questions that tapped into in-group culture relativism (Martinovic \& Verkuyten, 2013). Sample items are 'Our Dutch culture is certainly not better than other cultures', and 'How we perceive the world in the Netherlands is only one of the many possibilities' $(\alpha=.86, M=5.33, \mathrm{SD}=.95)$.

The mediator endorsement of common national identity was measured with three questions that asked about the importance of having an overarching national community, despite cultural diversity. ${ }^{3}$ Thus the emphasis was on the 'unity' aspect of unity in diversity, and this was assessed with items adapted from Gaertner, Rust, Dovidio, Bachman and Anastasio (1996): 'Even though the Netherlands is a culturally diverse society, I have the feeling we all belong to one community', 'In spite of the cultural differences, all groups together make up Dutch society', and 'Despite all the differences, I often have the feeling that we are one country and that we have to work together' $(\alpha=.90 ; M=4.15, \mathrm{SD}=1.47)$.

The dependent variable recognition of discrimination of immigrants was measured using three items: 'Immigrants are often being discriminated when applying for a job or an internship', 'Immigrants are often discriminated in nightlife settings', and 'In everyday life, immigrants often face discrimination' $(\alpha=.91$; $M=4.04, \mathrm{SD}=1.22$ ).

Table 1 shows the correlations between the core constructs. All the associations are significant and in the expected directions.

\section{Results}

\section{The Measurement Model}

A confirmatory factor analysis (CFA) was obtained from Mplus (version 7) to inspect whether the items for the recognition of discrimination, common national identity, power threat, and deprovincialization represent separate latent constructs. A model with four latent factors fitted the data very well, $\chi^{2}(59)=165.30$, $p<.001$, Comparative Fit Index $(\mathrm{CFI})=.988$, Tucker Lewis index $(\mathrm{TLI})=.983$, Root Mean Square Error Of Approximation (RMSEA) $=.044$ (low $=.036$, high $=.052)$, Standardized Root Mean Square Residual $($ SRMR $)=.028$. Each of

\footnotetext{
${ }^{3}$ It could be argued that these items measure the endorsement of multiculturalism. However, in the Netherlands multiculturalism is predominantly understood as the belief that the identity and cultural traditions of disadvantaged minority groups should be recognized and respected. Thus the focus is on acknowledging minority identities and the lack of attention to commonalities is a main reason for why multiculturalism has been strongly criticized and increasingly rejected (Verkuyten, 2014). The items do not focus on the recognition and minority identities but rather on the importance of national unity and cohesion despite cultural differences. Yet, in the European context it has been argued that an emphasis on unity in diversity is an important aspect of interculturalism (Cantle, 2012; Meer \& Modood, 2012) which means that the items can be considered to measure the endorsement of this particular aspect of interculturalism.
} 
Table 1 Correlations between the main constructs: Study $1(N=928)$ below the diagonal and Study 2 $(N=173)$ above the diagonal

\begin{tabular}{lllll}
\hline & 1 & 2 & 3 & 4 \\
\hline 1. Power threat & - & $-.51 * * *$ & $-.40 * * *$ & $-.42 * * *$ \\
2. Common national identity & $-.56 * * *$ & - & $.52 * * *$ & $.52 * * *$ \\
3. Deprovincialization & $-.39 * * *$ & $.48 * * *$ & - & $.37 * * *$ \\
4. Discrimination of immigrants & $-.33 * * *$ & $.39 * * *$ & $.33 * * *$ & - \\
\hline
\end{tabular}

Discrimination of immigrants: Study 1 recognition of discrimination against immigrants, Study 2 intention to protest against discrimination of immigrants

$* * * \quad p<.001$

the items loaded high on the designated factor, with loadings ranging from .61 to 95. Any combination of a three-factor solution (e.g., combining power threat with common dual belonging) yielded a significantly worse fit than a four-factor model. We are therefore confident that we are dealing with four empirically distinct constructs.

\section{Explaining Differences in Perceptions of Discrimination}

A structural model of recognition of discrimination was estimated that included power threat and deprovincialization as two independent predictors, and common identity as a mediator. We initially controlled for age, gender, education, and political orientation in relation to the mediator and the dependent variable, but we ultimately only kept the significant paths from the control variables in the model. These include the path from age to discrimination and from political orientation to common identity. This results in a more parsimonious model, while the findings and conclusions regarding the hypothesized relationships do not change.

The model fitted the data well, $\chi^{2}(83)=348.83, p<.001$, CFI $=.969$, TLI $=$ .962, RMSEA $=.059($ low $=.052$, high $=.065)$, SRMR $=.079$. The findings related to the hypothesized paths are presented in Fig. 1, and they are in line with the expectations. ${ }^{4}$ Stronger endorsement of a common national identity was related to higher perceived discrimination of minorities. Furthermore, power threat was associated with lower, and deprovincialization with higher, common identity. We used bootstrapping with 1000 replacement samples to obtain $95 \%$ confidence interval for indirect effects. An indirect effect is indicated by zero not falling within the confidence interval (Preacher \& Hayes, 2008). We found a significant indirect effect from power threat to discrimination via common identity, $b=-.112$, $t=-4.49, p<.001$ (lower $\mathrm{CI}=-.170$, higher $\mathrm{CI}=-.070$ ), and a significant indirect effect from deprovincialization to discrimination via common identity, $b=.114, t=4.13, p<.001$ (lower $\mathrm{CI}=.068$, higher $\mathrm{CI}=.176$ ). Significant direct paths did remain from power threat to discrimination, $b=-.134, t=-2.97$,

\footnotetext{
${ }^{4}$ Regarding the control variables, older participants perceived more discrimination of minorities, $b=.006, t=2.66, p=.008$, and those with a more right wing political orientation endorsed the idea of common belonging less, $b=-.129, t=-3.83, p<.001$.
} 


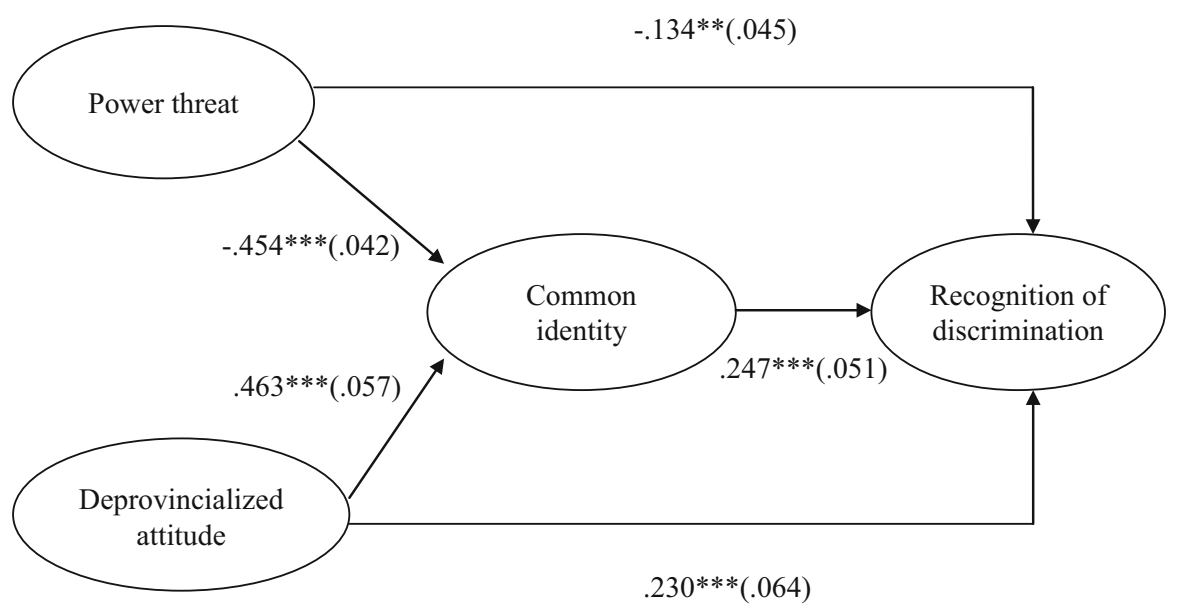

Fig. 1 A path model explaining differences in native Dutch people's recognition of discrimination of immigrants $(N=928)$. Note Unstandardized coefficients with standard errors in the brackets. Paths from the control variable political orientation to the mediator and from age to the dependent variable were accounted for in the model. $* * p<.01 ; * * * p<.001$

$p=.003$, and from deprovincialization to discrimination, $b=.230, t=3.58$, $p<.001$, indicating partial mediation.

We also tested an alternative model in which common identity was specified as a predictor of power threat and deprovincialization, which in turn were directly related to the recognition of discrimination. We included the significant paths from age to discrimination, from education to power threat and from age and education to deprovincialization. This model also had a good fit, $\chi^{2}(82)=221.44, p<.001$, $\mathrm{CFI}=.984, \mathrm{TLI}=.980, \mathrm{RMSEA}=.043(\mathrm{low}=.036$, high $=.050)$, SRMR $=$ .031 , but the indirect paths were weaker. The path from common identity via deprovincialization to discrimination was positive, $b=.072, t=3.56, p<.001$ (lower $\mathrm{CI}=.033$, higher $\mathrm{CI}=.113$ ), whereas the path via power threat was negative, $b=-.082, t=3.03, p=.002$ (lower $\mathrm{CI}=.027$, higher $\mathrm{CI}=.132$ ). These findings suggest that there is more support for our theoretically guided model in terms of causal reasoning, but the model with reverse causality is also plausible.

\section{Discussion}

As expected the findings show that higher perceived power threat is associated with a lower endorsement of a common national identity representation that acknowledges cultural diversity (unity in diversity), which, in turn, is related to lower recognition of discrimination of immigrants. Deprovincialization, in contrast, is associated with a stronger sense of common identity, thereby with a stronger recognition of discrimination. Importantly, these results were found among a representative sample of the native Dutch population and when controlling for relevant demographic characteristics. Thus, when majority members feel a threat to 
their group's power they tend to reject a one-group representation in which the emphasis is on a shared national identity despite cultural diversity, which, in turn, is associated with the recognition of the discrimination that immigrants face. On the other hand, being able to look beyond one's in-group's norms and standards (a deprovincialized outlook) is associated with stronger awareness of the presence of discrimination in society, via a sense of common national belonging that acknowledges cultural diversity.

\section{Study 2}

The goal of Study 2 was to examine whether the findings obtained in Study 1 generalize to majority members' intention to protest on behalf of immigrants. Recognizing discrimination of immigrants is a first step in doing something about it but does not have to imply that one is willing to take action against this form of injustice. Ideologies that justify the status quo (Sidanius \& Pratto, 1999) and psychological tendencies of system justification (Jost, Banaji, \& Nosek, 2004) reduce the likelihood of wanting to correct group-based disparities. There is often a 'principle-implementation gap', whereby majority members endorse the principle of equality but do not support social change policies and actions, such as protest on behalf of a disadvantaged group (Dixon, Durrheim, \& Tredoux, 2007; see also Yogeeswaran \& Dasgupta, 2014). This kind of protest directly challenges groupbased inequalities and in-group privileges and can elicit social disapproval and resistance from other majority group members.

\section{Method}

\section{Data and Participants ${ }^{5}$}

Dutch natives aged 19 to $81(M=51.77, \mathrm{SD}=16.24 ; 48 \%$ female $)$ took part in this online study $(N=173)$. Data were again collected by the same Dutch bureau but among a different sample of the native Dutch that represents the adult native Dutch population in terms of the main demographic characteristics. In terms of political self-placement, $27.8 \%$ of the participants placed themselves at the political left, $27.7 \%$ in the middle, and $27.1 \%$ at the right, and $17.9 \%$ did not indicate a political orientation.

\section{Measures}

Perceived power threat $(M=3.93, \mathrm{SD}=1.44)$, the endorsement of a common national identity representation $(M=4.61, \mathrm{SD}=1.64)$, and deprovincialization

\footnotetext{
${ }^{5}$ Parts of these data have been used elsewhere (Verkuyten, Martinovic, \& Smeekes, 2014) but the current findings have not been published previously. The sample size in this study was smaller compared to Study 1 because of financial limitations.
} 
$(M=5.48, \mathrm{SD}=1.34)$ were measured with similar items used in Study $1(\alpha=.86$, $\alpha=.88$, and $\alpha=.87$, respectively).

For measuring participants' intention to protest against the discrimination of immigrants we used the following introduction: 'Various studies have demonstrated that discrimination of immigrants in applying for a job, at work and in everyday life happens quite often. How likely is it that you would do one of the following things to protest against discrimination of immigrants in the Netherlands'? Subsequently, a list of four actions was given: (1) sign a petition against discrimination, (2) participate in an anti-discrimination demonstration, (3) donate money for an antidiscrimination campaign, and (4) put up an anti-discrimination window poster. Participants were asked to indicate the likelihood of participating in these actions on a 5 -point scale $(1=$ no, certainly not, $5=$ yes, certainly). The items formed a reliable scale $(\alpha=.80, M=2.24, \mathrm{SD}=.83)$.

The correlations between the main constructs are significant and in the expected directions (Table 1).

\section{Results}

\section{The Measurement Model}

A CFA in Mplus (version 7) yielded a four-factor solution for the items measuring power threat, deprovincialization, common identity, and the intention to protest against the discrimination of immigrants. The model had a good fit, $\chi^{2}(71)=$ 134.62, $p<.001, \quad$ CFI $=.952, \quad$ TLI $=.939, \quad$ RMSEA $=.072 \quad($ low $=.053$, high $=.090)$, SRMR $=.058$, and all the items had high loadings on the designated factor (.64-.95). The four-factor solution fitted the data better than any other combination of three factors (e.g., common identity and deprovincialization being combined into one factor). This again confirms that the four theoretical constructs are measured in an empirically distinct way.

\section{Explaining Differences in Intentions to Protest}

We estimated a structural model with protest against the discrimination of immigrants serving as the dependent variable, power threat and deprovincialization as main predictors, and common identity as a mediator. We again controlled for age, gender, education, and political orientation in relation to the mediator and the dependent variable. Only the significant paths from political orientation to the mediator common identity and to the dependent variable protest were kept in the model.

The model had a good fit, $\chi^{2}(157)=290.24, p<.001$, CFI $=.924$, TLI $=.909$, $\mathrm{RMSEA}=.070($ low $=.057$, high $=.083), \mathrm{SRMR}=.063$. The relations are in line with our hypotheses and with the findings from Study 1 (see Fig. 2). ${ }^{6}$ Power

\footnotetext{
${ }^{6}$ As to control variables, participants with a more right wing political orientation endorsed the idea of common belonging less, $b=-.255, t=-2.37, p=.018$, and they were less willing to protest against discriminatory treatment of ethnic minorities, $b=-.190, t=-2.11, p=.002$.
} 


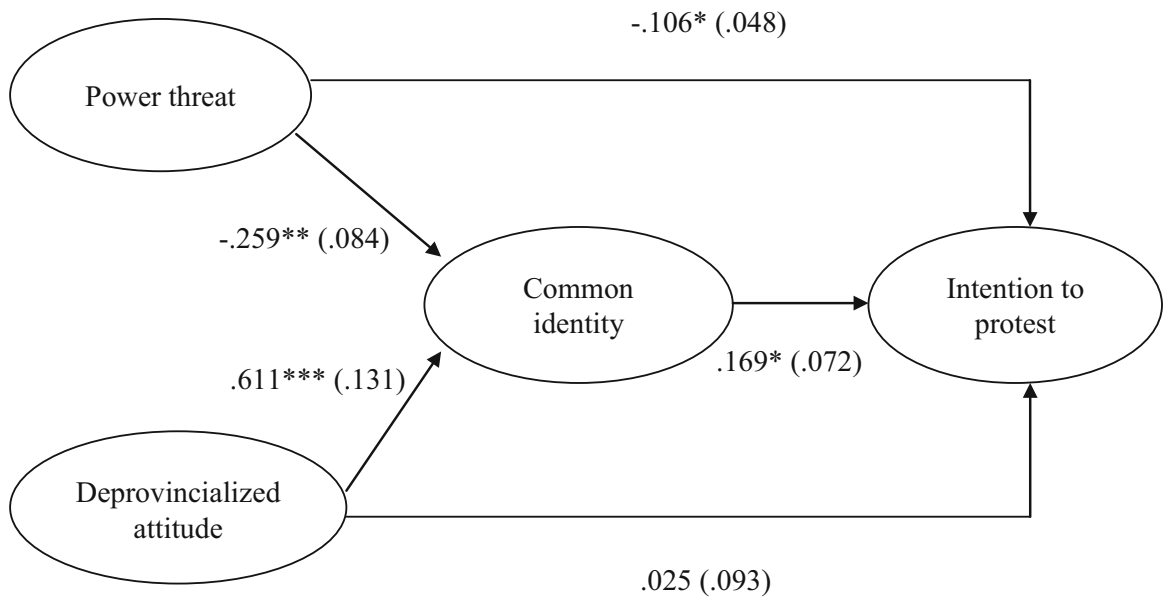

Fig. 2 A path model explaining differences in the intention of native Dutch to protest against discrimination of immigrants $(N=173)$. Note Unstandardized coefficients with standard errors in the brackets. Paths from the control variable political orientation to the mediator and to the dependent variable were accounted for in the model. * $p<.05 ; * * p<.01 ; * * p<.001$

threat was related to a weaker and deprovincialization to a stronger sense of common identity. Further, Dutch natives who had a sense of common national identity reported higher intention to protest against discrimination of minorities. Applying the same bootstrapping technique as in Study 1 (see Preacher \& Hayes, 2008), we found the expected significant indirect effects. Power threat was, via lower common identity, related to a lower intention to protest against discrimination of minorities, $b=-.044, t=-1.99, p=.046$ (lower $\mathrm{CI}=-.105$, higher $\mathrm{CI}=-.013$ ), whereas deprovincialization was related to a higher intention to protest, due to a stronger sense of common identity, $b=.103, t=2.06, p=.039$ (lower CI $=.031$, higher $\mathrm{CI}=.249$ ). The relationship between deprovincialization and intention to protest was fully explained by common national identity: The remaining direct effect was not significant, $b=.025, t=0.27, p>.10$. In contrast, the direct path from power threat to discrimination was significant, $b=-.106$, $t=-2.21, p=.027$, suggesting partial mediation.

We again estimated an alternative model with common identity as a predictor of power threat and deprovincialization, which were then related to the intention to protest. We included the significant paths from political orientation to protest intention, $b=-.184, t=-3.01, p=.003$, and from education to power threat, $b=-.227, t=-2.97, p=.003$. This model also had a good fit, $\chi^{2}(96)=180.38$, $p<.001$, CFI $=.940$, TLI $=.926$, RMSEA $=.071$ (low $=.055$, high $=.087)$, $\mathrm{SRMR}=.064$. The path from common identity via power threat to intention to protest was significant, $b=.054, t=2.06, p=.040$ (lower $\mathrm{CI}=.011$, higher $\mathrm{CI}=.113$ ), but the path via deprovincialization was not significant, $b=.009$, $t=0.24, p=.812$ (lower CI $=-.068$, higher $\mathrm{CI}=.092$ ). This is due to the fact that deprovincialization was not directly related to the intention to protest, $b=.022$, $t=0.24, p=.811$. Thus, deprovincialization had an indirect effect on the intention 
to protest via power threat (original model), but power threat had no indirect effect on protest via deprovincialization (alternative model).

\section{Discussion}

Focusing on the intention to protest against discrimination on behalf of immigrants, the findings of Study 2 provide further support for the roles of perceived power threat, deprovincialization, and a sense of common national belonging (unity in diversity). Higher power threat was again related to a weaker endorsement of common identity, which, in turn, was related to more protest intention. Thus, when majority members feel a threat to their group's power they tend to reject a onegroup representation of the nation that acknowledges cultural diversity, and this is indirectly related to the willingness to protest against discrimination of immigrants. Furthermore, deprovincialization turned out to be related to a higher protest intention. This was because Dutch natives with a less provincial view on their ingroup's norms and values were more likely to have a sense of a common national identity that recognizes cultural diversity.

\section{General Discussion}

Understanding when and why majority group members recognize the discrimination that immigrants face and are willing to take action against discriminatory practices has obvious practical implications. Because of their dominant position and greater resources, majority members play an important role in achieving equality and social change. Yet, research has predominantly focused on collective action by immigrantorigin groups (Fleischmann et al., 2011; Simon \& Grabow, 2010; Simon \& Ruhs, 2008) and has largely ignored the perspective of the majority (Banfield \& Dovidio, 2013; Subašiç \& Reynolds, 2009).

In two studies with national samples, the present research examined whether the endorsement of a common national identity representation that acknowledges cultural differences (unity in diversity) is associated with increased recognition of discrimination of immigrants and greater willingness to protest against it. Furthermore, it was examined whether perceived power threat and deprovincialization reduce the endorsement of a common identity representation and thereby the recognition of discrimination and protest. The findings of both studies provide supporting evidence for the expected associations and support the theoretical propositions of the social identity perspective (Turner \& Reynolds, 2001).

First, political solidarity is more likely when majority members redefine minorities as an in-group and develop a sense of unity in diversity (Subašić et al., 2008). Solidarity implies higher-level unity and the common in-group identity model (Gaertner \& Dovidio, 2000) argues that a one-group representation facilitates the recognition of ethnic group disadvantages and helps to establish a context of moral inclusion with the related justice concerns for all members included in the superordinate category (Dovidio et al., 2009; Huo, 2003; Tyler \& Blader, 2003). The findings in both studies showed that a higher endorsement of a 'unity in 
diversity' representation of the national category was associated with higher recognition of discrimination that immigrants face and stronger willingness to take action against this form of exclusion.

Second, the findings suggest that there are independent out-group focused (power threat) and in-group focused (deprovincialization) influences on perceptions of discrimination and the willingness to protest against it. According to the group position theory (Blumer, 1958; Bobo, 1999), people who feel a threat to their group's power will tend to defend their position and thus can be expected to be less likely to endorse a common identity representation that includes immigrants and minority groups. This turned out to be the case in both studies, and it demonstrates that perceived power threat can play an indirect negative role in discrimination recognition and the willingness to protest against discrimination of immigrants. Majority members who feel that minorities threaten the power of their group are more likely to resist a common national identity that recognizes cultural diversity. Yet, and in addition to these indirect effects, higher perceived power threat was also directly associated with lower perceptions of discrimination and willingness to protest. This indicates that this type of threat makes it difficult to acknowledge and challenge discrimination that contributes to the maintenance of group-based social hierarchies (Sidanius \& Pratto, 1999). One possible reason for this is that feelings of threat legitimize discriminatory behavior against immigrants (Pereira, Vala, \& Costa-Lopez, 2010). This legitimizing role of threat perceptions could be examined as an additional mediating mechanism in future studies. Furthermore, future studies could examine whether this legitimizing role depends on individual differences in, for example, authoritarianism and just world beliefs (Lima-Nunes, Pereira, \& Correia, 2013).

The findings further show that a more deprovincialized (less in-group centric) worldview is associated with a stronger endorsement of a shared representation of the national category and, via this endorsement, to the perception of discrimination and intention to protest. Majority members' who have a more deprovincialized understanding of their in-group culture tend to acknowledge and recognize the value of other cultures (Pettigrew, 1997). The findings show that higher deprovincialization was associated relatively strongly with the endorsement of national unity in diversity. Furthermore, in Study 2 the effect of deprovincialization on the willingness to protest against discrimination of immigrants was fully mediated by common national identity. Yet, in Study 1 there was also a direct effect, which suggests that additional mechanisms might be involved in this relationship. One possibility for future studies is to examine whether a less in-group centric worldview implies enhanced perspective taking, which has been found to reduce negative out-group attitudes (Galinski \& Moskowitz, 2000).

Some limitations of the current research should be considered. Much of the research on social identity and attitudes toward minority groups examines student samples (Henry, 2008), while we used two national samples. Yet, the research was conducted in one particular country with its own history of immigration. Countries differ in many ways and representations of national identity vary depending on the historical and socio-political context. These differences might be important for understanding the role of perceived power threat, deprovincialization and common national identity for the recognition of discrimination of immigrants and one's 
willingness to protest against it (Guimond et al., 2013). Future studies should examine the generality of the current findings in other national contexts.

Furthermore, although we examined both the recognition of discrimination and the willingness to protest, we did not investigate behavior, such as actually donating money or signing a petition. Although protest intentions and behavior tend to be associated (Van Zomeren et al., 2008), it remains to be seen whether the current results hold for actual protest.

Another limitation that should be acknowledged is that no causal inferences can be drawn because the two studies were cross-sectional. The order of associations examined was theoretically derived, and there is also experimental evidence that a common identity representation promotes the intention to protest against discrimination of minority members (Banfield \& Dovidio, 2013). Yet, it is, for example, also possible that common identity endorsement reduces feelings of power threat and stimulates a more deprovincialized worldview (Riek, Mania, Gaertner, McDonals, \& Lamoreaux, 2010). In both Studies, this alternative model also fitted the data but compared to the proposed model the indirect effects were weaker or not significant. It is the combination of theoretical considerations, fit indices of models, and significance tests of the indirect effects that gives the best understanding of the mechanisms involved (Danner, Hagemann, \& Fiedler, 2014). It is likely, however, that the relationships are not unidirectional and that the different constructs influence each other. The present results, then, show possible and plausible directions of mutual influences between feelings of threat, deprovincialization and the endorsement of a common national identity that acknowledges cultural diversity. As such they provide part of the answer to the complex question of the social psychological factors that underlie majority members' recognition of discrimination of immigrants and their willingness to protest against it. Future studies should use experimental and longitudinal designs for examining the proposed causal order and the possibility of bidirectional relationships.

In conclusion, using two national samples the similar results in both studies support the generality of the findings and add to the limited but important research on when and why majority members recognize group-based injustices and are willing to protest on behalf of disadvantaged minority groups (Banfield \& Dovidio, 2013; Saguy et al., 2008; Subašiç \& Reynolds, 2009). The results show the importance of national identity representations and the relevance of considering out-group focused (perceived threats) and in-group focused (deprovincialization) determinants. Given the findings, future studies are advised to investigate other majority groups in other countries and to consider additional mediating processes (e.g., perspective taking ability) and moderating conditions (e.g., just world beliefs).

Open Access This article is distributed under the terms of the Creative Commons Attribution 4.0 International License (http://creativecommons.org/licenses/by/4.0/), which permits unrestricted use, distribution, and reproduction in any medium, provided you give appropriate credit to the original author(s) and the source, provide a link to the Creative Commons license, and indicate if changes were made. 


\section{References}

Ashmore, R. D., Deaux, K., \& McLaughlin-Volpe, T. (2004). An organizing framework for collective identity: Articulation and significance of multidimensionality. Psychological Bulletin, 130, 80-114.

Banfield, J. C., \& Dovidio, J. (2013). Whites' perceptions of discrimination against Blacks: The influence of common identity. Journal of Experimental Social Psychology, 49, 833-841.

Blumer, H. (1958). Race prejudice as a sense of group position. The Pacific Sociological Review, 1, 3-7.

Bobo, L. D. (1999). Prejudice as group position: Microfoundations of a sociological approach to racism and race relations. Journal of Social Issues, 55, 445-472.

Branscombe, N., Ellemers, N., Spears, R., \& Doosje, B. (1999). The context and content of social identity threat. In N. Ellemers, R. Spears, \& B. Doosje (Eds.), Social identity: Context, commitment, content (pp. 35-58). Oxford: Blackwell.

Brewer, M. B. (2008). Deprovincialization: Social identity complexity and outgroup acceptance. In U. Wagner, L. R. Tropp, G. Finchilescu, \& C. Tredoux (Eds.), Improving intergroup relations: Building on the legacy of Thomas F. Pettigrew (pp. 160-176). Oxford: Blackwell.

Cantle, T. (2012). Interculturalism: The new era of cohesion and diversity. London: Palgrave-Macmillan.

Danner, D., Hagemann, D., \& Fiedler, K. (2014). Mediation analysis with structural equation models: Combining theory, design, and statistics. European Journal of Social Psychology (early view). doi:10.1002/ejsp.2106.

Dixon, J., Durrheim, T., \& Tredoux, C. (2007). Intergroup contact and attitudes towards the principle and practice of racial equality. Psychological Science, 18, 867-872.

Dovidio, J. F., Gaertner, S. L., \& Saguy, T. (2009). Commonality and the complexity of 'we': Social attitudes and social change. Personality and Social Psychology Review, 13, 3-20.

Dovidio, J. F., Hewstone, M., Glick, P., \& Esses, V. M. (Eds.). (2010). The Sage handbook of prejudice, stereotyping and discrimination. London: Sage.

Ellemers, N., Spears, R., \& Doosje, B. (2002). Self and social identity. Annual Review of Psychology, 53, 161-186.

Fleischmann, F., Phalet, K., \& Klein, O. (2011). Religious identification and politicization in the face of discrimination: Support for political Islam and political action among the Turkish and Moroccan second generation in Europe. British Journal of Social Psychology, 50, 628-648.

Gaertner, S. L., \& Dovidio, J. F. (2000). Reducing intergroup bias: The common ingroup identity model. Hove: Psychology Press.

Gaertner, S. L., Rust, M. C., Dovidio, J. F., Bachman, B. A., \& Anastasio, P. A. (1996). The contact hypothesis: The role of a common in-group identity on reducing intergroup bias among majority and minority group members. In J. L. Nye \& A. M. Brower (Eds.), What's social about social cognition? (pp. 230-260). Newbury park, CA: Sage.

Galinski, A. D., \& Moskowitz, G. B. (2000). Perspective-taking: Decreasing stereotype expression, stereotype accessibility, and in-group favoritism. Journal of Personality and Social Psychology, 78, 708-724.

Guimond, S., Crisp, R. J., De Oliveira, P., Kamiejski, R., Kteily, N., Kuepper, B., et al. (2013). Diversity policy, social dominance, and intergroup relations: Predicting prejudice in changing social and political contexts. Journal of Personality and Social Psychology, 104, 941-958.

Henry, P. J. (2008). College sophomores in the laboratory redux: Influences of a narrow data base on social psychology's view of the nature of prejudice. Psychological Inquiry, 19, 49-71.

Hindriks, P., Verkuyten, M., \& Coenders, M. (2014). Dimensions of social dominance orientation: The roles of legitimizing myths and national identification. European Journal of Personality, 28, 538-549.

Hindriks, P., Verkuyten, M., \& Coenders, M. (2015). The evaluation of immigrants' political acculturation strategies. International Journal of Intercultural Relations, 47, 131-142.

Hornsey, M. J., \& Hogg, M. A. (2000). Assimilation and diversity: An integrative model of subgroup relations. Personality and Social Psychology Review, 4, 143-156.

Huo, Y. J. (2003). Procedural justice and regulation across group boundaries: Does subgroup identity undermine relationship-based governance. Personality and Social Psychology Bulletin, 29, $336-348$.

Jost, J. T. (2006). The end of the end of ideology. American Psychologist, 61, 651-670. 
Jost, J. T., Banaji, M., \& Nosek, B. A. (2004). A decade of system justification theory: Accumulated evidence of conscious and unconscious bolstering of the status quo. Political Psychology, 25, 881-919.

Knowles, E. D., Lowery, B. S., Chow, R. M., \& Unzueta, M. M. (2014). Deny, distance, or dismantle? How white Americans manage a privileged identity. Perspectives on Psychological Science, 9 , 594-609.

Lima-Nunes, A., Pereira, C. R., \& Correia, I. (2013). Restricting the scope of justice to justify discrimination: The role played by justice perceptions in discrimination against immigrants. European Journal of Social Psychology, 43, 627-636.

Major, B., Quinton, W. J., \& McCoy, S. K. (2002). Antecedents and consequences of attributions to discrimination: Theoretical and empirical advances. In M. Zanna (Ed.), Advances in experimental social psychology (Vol. 34, pp. 251-330). New York: Academic Press.

Martinovic, B., \& Verkuyten, M. (2013). We were here first, so we determine the rules of the game': Autochthony and prejudice toward outgroups. European Journal of Social Psychology, 43, 637-647.

Meer, N., \& Modood, T. (2012). How does interculturalism contrast with multiculturalism? Journal of Intercultural Studies, 33, 175-196.

Pereira, C., Vala, J., \& Costa-Lopez, R. (2010). From prejudice to discrimination: The legitimizing role of perceived threat in discrimination against immigrants. European Journal of Social Psychology, 40, 1231-1250.

Pettigrew, T. F. (1997). Generalized intergroup contact effects on prejudice. Personality and Social Psychology Bulletin, 23, 173-185.

Preacher, K. J., \& Hayes, A. F. (2008). Asymptotic and resampling strategies for assessing and comparing indirect effects in multiple mediator models. Behavior Research Methods, 40, 879-891.

Rattan, A., \& Ambady, N. (2013). Diversity ideologies and intergroup relations: An examination of colorblindness and multiculturalism. European Journal of Social Psychology, 43, 12-21.

Reicher, S., Cassidy, C., Wolpert, L., Hopkins, N., \& Levina, M. (2006). Saving Bulgaria's Jews: An analysis of social identity and the mobilization of social solidarity. European Journal of Social Psychology, 36, 49-72.

Riek, B. M., Mania, E. W., Gaertner, S. L., McDonals, S. A., \& Lamoreaux, M. J. (2010). Does a common identity reduce intergroup threat? Group Processes and Intergroup Relations, 13, 403-423.

Saguy, T., Dovidio, J. F., \& Pratto, F. (2008). Beyond contact: Intergroup contact in the context of power relations. Personality and Social Psychology Bulletin, 43, 432-445.

Schmitt, M. T., \& Branscombe, N. R. (2002). The meaning and consequences of perceived discrimination in disadvantaged and privileged social groups. In W. Stroebe \& M. Hewstone (Eds.), European Review of Social Psychology (Vol. 12, pp. 167-199). London: Wiley.

Sidanius, J., \& Pratto, F. (1999). Social dominance: An intergroup theory of social hierarchy and oppression. Cambridge: Cambridge University Press.

Simon, B., \& Grabow, O. (2010). The politicization of migrants: Further evidence that politicized collective identity is a dual identity. Political Psychology, 31, 717-738.

Simon, B., \& Ruhs, D. (2008). Identity and politicization among Turkish migrants in Germany: The role of dual identification. Journal of Personality and Social Psychology, 95, 1354-1366.

Smeekes, A., Verkuyten, M., \& Poppe, E. (2012). How a tolerant past affects the present: Historical tolerance and the acceptance of Muslim expressive rights. Personality and Social Psychology Bulletin, 38, 1410-1422.

Smith, H. J., \& Tyler, T. R. (1996). Justice and power: When will justice concerns encourage the advantaged to support policies which redistribute economic resources and the disadvantaged tom willingly obey the law? European Journal of Social Psychology, 26, 171-200.

Subašiç, E., \& Reynolds, K. J. (2009). Beyond "practical” reconciliation: Intergroup inequality and the meaning of non-indigenous identity. Political Psychology, 30, 243-267.

Subašić, E., Reynolds, K. J., \& Turner, J. C. (2008). The political solidarity model of social change: Dynamics of self-categorization in intergroup power relations. Personality and Social Psychology Review, 12, 330-351.

Tajfel, H., \& Turner, J. C. (1979). An integrative theory of intergroup conflict”. In W. G. Austin \& S. Worchel (Eds.), The social psychology of intergroup relations (pp. 33-47). Monterey, CA: Brooks/ Cole.

Turner, J. C. (1999). Some current issues in research on social identity and self-categorization theories. In N. Ellemers, R. Spears, \& B. Doosje (Eds.), Social identity: Context, commitment, content (pp. 6-34). Oxford: Blackwell. 
Turner, J. C., Hogg, M. A., Oakes, P. J., Reicher, S. D., \& Wetherell, M. S. (1987). Rediscovering the social group: A self-categorization theory. Oxford: Blackwell.

Turner, J. C., \& Reynolds, K. J. (2001). The social identity perspective in intergroup relations: Theories, themes and controversies. In R. Brown \& S. Gaertner (Eds.), Blackwell handbook of social psychology: Intergroup processes (pp. 133-152). Oxford: Blackwell.

Tyler, T., \& Blader, S. L. (2003). The group engagement model: Procedural justice, social identity, and cooperative behavior. Personality and Social Psychology Review, 7, 349-361.

Van Zomeren, M., Postmes, T., \& Spears, R. (2008). Toward an integrative social identity model of collective action: A quantitative research synthesis of three socio-psychological perspectives. Psychological Bulletin, 134, 504-535.

Verkuyten, M. (2006). Multicultural recognition and ethnic minority rights: A social identity perspective. In W. Stroebe \& M. Hewstone (Eds.), European Review of Social Psychology (Vol. 17, pp. 148-184). London: Wiley.

Verkuyten, M. (2014). Identity and cultural diversity: What social psychology can teach us. Hove: Routledge.

Verkuyten, M., Martinovic, B., \& Smeekes, A. (2014). The multicultural jigsaw puzzle: Category indispensability and the acceptance of immigrants' cultural rights. Personality and Social Psychology Bulletin, 40, 1480-1493.

Wright, S. C., \& Baray, G. (2012). Models of social change in social psychology: Collective action or prejudice reduction? Conflict or harmony? In J. Dixon \& M. Levine (Eds.), Beyond prejudice: Extending the social psychology of conflict, inequality and social change (pp. 225-247). Cambridge: Cambridge University Press.

Yogeeswaran, K., \& Dasgupta, N. (2014). The devil is in the detail: Abstract versus concrete construals of multiculturalism differently impact intergroup relations. Journal of Personality and Social Psychology, 106, 772-789. 